\title{
Evaluation of various means of transport for urban areas
}

Helmut Brunner ${ }^{1 *}$, Mario Hirz ${ }^{1}$, Wolfgang Hirschberg ${ }^{1}$ and Kurt Fallast ${ }^{2}$

\begin{abstract}
Background: Personal transportation in urban areas is characterised by different transportation technologies with significantly varying properties regarding usability, infrastructural requirements and environmental impacts. This characterisation motivates the objective evaluation of mobility solutions, based on different criteria. State of the art evaluations in the scientific literature mainly focus on one specific criterion at a time. The most common criteria investigated are found in energy demand or equivalent fuel consumption. Other parameters include the traffic space demand or mean velocity as a reference for the user-related criterion "travel time". Since different modes of transport show various potentials in different criteria, an interesting point for scientific research is consideration of the different criteria in a more comprehensive evaluation approach. To address this issue, the aim of this study is to present a new approach for an objective evaluation and comparison of different transport technologies under consideration of pre-defined range of criteria and defined boundary conditions and requirements for personal mobility in cities. Besides technical-oriented aspects like driving range, transport capability and life cycle-related consumption of resources, additional factors influencing user-behaviour and traffic density are reflected. The evaluation method is presented, based on a generated exemplary data collection regarding technical and in-use characteristics of different modes of transport, mainly investigated in the city of Graz, Austria.
\end{abstract}

Methods: The study focuses on different means of transport, in particular walking, bicycling, the use of powered two-wheelers, passenger cars with different propulsion systems and public transport systems. It is based on the determination of selected criteria, considering ecologic, infrastructural and user-related aspects. With respect to ecologic criteria, the study considers resources and energy consumption as also the resulting $\mathrm{CO}_{2}$ equivalent emissions. The mean velocity and transport capacity are considered in the context of user-related criteria. Traffic space demand is an important and limited resource, especially in urban areas. The present study thus includes the determination and comparison of the relative traffic and parking space demands for the different modes of transport. The evaluation is based on a specifically developed evaluation methodology, considering weighted traffic performance indices, which are also proposed and discussed.

Results: Within the present study, a database providing specific mobility-related criteria and parameters has been generated, representing technical characteristics and the effects of the use of different vehicles and means of transportation in urban areas. The illustrated results allow an objective evaluation of a broad range of different means of transportation and vehicles, based on introduced "weighted traffic performance indices" (WTPI).

\footnotetext{
* Correspondence: helmut.brunner@tugraz.at; http://www.ftg.tugraz.at

${ }^{1}$ Institute of Automotive Engineering, Graz University of Technology,

Inffeldgasse 11/2, 8010 Graz, Austria

Full list of author information is available at the end of the article
} 
(Continued from previous page)

Conclusions: The study contributes to a discussion of transportation technologies and allows a derivation of measures for further research topics to face future intra-urban mobility demands. This represents a basis for decision making on the priorisation of the most suitable transport systems for urban areas. It is shown that the motorised individual passenger transport as dominated by the use of private passenger cars in particular represents today the most inefficient form of inner-urban mobility.

Keywords: Urban transport, Urban traffic, Urban mobility, Environmental impacts evaluation, Energy demand, Equivalent fuel consumption, Traffic space requirement

\section{Background}

Personal transportation in urban areas is characterised by different transportation technologies with significantly varying properties regarding usability, infrastructural requirements and environmental impacts. Today, the private passenger car is still the most important mode of transport across the world. About $70 \%$ of so-called motorised individual passenger transport (MIT, passenger car and powered two-wheelers) is in cities and congested areas, [1, 2]. In general, the global energy demand for individual mobility is mainly supplied by crude oil-based fuels. Improvements in powertrain efficiency and energy consumption reduction strategies are partly compensated by increasing motorisation, traffic performance and vehicle masses. In the European Union, the annual energy consumption growth rate of $1.3 \%$ is mainly caused by the rising number of passenger cars and increasing traffic performance, [1]. In automotive engineering, energy consumption and exhaust emission reduction are still the main drivers for research and development. Electrification, innovative drive systems, alternative energy storage and lightweight construction play important roles as innovations.

Apart from energy consumption and resulting exhaust emissions of technologies for individual mobility, it is also important to take further influencing factors into consideration-especially in urban areas. Examples are the space demand in parking and fluent traffic (with resultant traffic congestions), space demand and the costs of energy supply infrastructures (e.g. electric charging stations), traffic safety or noise. For these reasons, it is essential that the focus is not only on the vehicle itself. New approaches provide an integration of technologies for individual mobility into entire mobility systems. By this means a smart combination of different transportation technologies is able to support successful sustainable urban development and energy supply strategies.

With the motivation to facilitate the development of innovative transport concepts, the present study focuses on an objective evaluation of different existing means of transport in urban areas. State of the art evaluations of transportation technologies focus on one specific criterion at a time, e.g. the energy demand or equivalent fuel consumption [3-6]. But there are more criteria which must also be evaluated, e.g. the traffic space demand or mean velocity as a reference for the user-related criterion "travel time". A special challenge lies in the combination of different criteria to enable comprehensive evaluation and in-depth discussion of different transportation modes. A detailed evaluation based on a wide range of different criteria provides the incentive and the challenge to combine the various, partially conflicting criteria in a smart, objective and representative way.

\section{Aim of this study}

The present study aims at a comprehensive evaluation of different means of transport for urban traffic. On this basis, it introduces a new approach for the assessment of different modes of transport, including walking, bicycling, the use of powered two-wheelers (PTW), passenger cars with different propulsion systems and public transport systems. It is based on the determination of an election of different criteria, considering ecological, infrastructural and user-related aspects.

The main objectives of the present study include the following items:

1) The collection of data concerning the use of different modes of transport in urban areas in an exemplary urban region. The study was conducted in the city of Graz, Austria.

2) The development of a methodology for the evaluation of different modes of transport, based on the consideration of a broad range of pre-defined criteria.

3) The evaluation itself of different modes of transport based on the introduced methodology and presented data.

\section{Limitations}

The objective evaluation is based on a limited selection of criteria for different vehicles and modes of transport. Aspects, which are not able to be considered in this work, are efforts concerning the provision of infrastructure, e.g. for the construction and maintenance of streets, roads and rail tracks. The developed evaluation methodology is transferable to other cities. Since the data collected is derived mainly from a single specific urban region (Graz), the results may be subject to change. Furthermore, the 
evaluation is based on neutralised, physically based comparison indices. In the sense of a scientific evaluation, the consideration is strictly related to purely rational criteria such as average journey speed or energy consumption. Finally, the study does not consider the cost aspects for customers and/or communities.

\section{Methods}

In a first step, the majority of common in-use vehicles and means of transport are detected and categorised. Technical and in-use characteristics are then investigated via analysis of existing data in scientific literature and conduction of measurement drives in the urban area of Graz. The investigated characteristics and results are illustrated in Table 1. Further details on specific processes for determination are included in the subsequent sections. In a second step, an evaluation methodology is developed, which takes a smart combination of different evaluation criteria into consideration. Selected criteria in the present results include resource demand, space demand in fluent and parking traffic, and the average journey speed as a user-related criterion. Finally, an evaluation is carried out using all the collected data. Further details about this are provided in the subsequent sections.

Table 1 Collected data for the means of transport considered

\begin{tabular}{|c|c|c|c|c|c|c|c|}
\hline & $\begin{array}{l}\text { Max. number } \\
\text { of persons [\#] }\end{array}$ & $\begin{array}{l}\text { Occupancy } \\
\text { rate }[\%]\end{array}$ & $\begin{array}{l}\text { Eff. number of } \\
\text { persons [\#] }\end{array}$ & $\begin{array}{l}\text { Traffic space demand } \\
{\left[\mathrm{m}^{2}\right]}\end{array}$ & $\begin{array}{l}\text { Traffic space demand } \\
{\left[\mathrm{m}^{2} / \mathrm{P}\right]}\end{array}$ & $\begin{array}{l}\text { Parking space } \\
\text { demand }\left[\mathrm{m}^{2}\right]\end{array}$ & $\begin{array}{l}\text { Parking space } \\
\text { demand }\left[\mathrm{m}^{2} / \mathrm{P}\right]\end{array}$ \\
\hline Pedestrian & 1 & 100 & 1.00 & 2.0 & 2.0 & 0.0 & 0.0 \\
\hline Bicycle & 1 & 100 & 1.00 & 4.4 & 4.4 & 1.0 & 1.0 \\
\hline E-bicycle & 1 & 100 & 1.00 & 4.4 & 4.4 & 1.0 & 1.0 \\
\hline Scooter & 2 & 55 & 1.10 & 10.3 & 9.4 & 2.0 & 1.8 \\
\hline E-scooter & 2 & 55 & 1.10 & 10.3 & 9.4 & 2.0 & 1.8 \\
\hline Light urban EV & 2 & 55 & 1.10 & 22.0 & 20.0 & 4.3 & 3.9 \\
\hline Subcompact PC & 4 & 27 & 1.07 & 25.5 & 23.8 & 7.9 & 7.3 \\
\hline Subcompact EV & 4 & 27 & 1.07 & 25.5 & 23.8 & 7.9 & 7.3 \\
\hline Mid class PC & 5 & 27 & 1.34 & 27.6 & 20.6 & 9.8 & 7.3 \\
\hline Mid class PHEV & 5 & 27 & 1.34 & 27.6 & 20.6 & 9.8 & 7.3 \\
\hline Luxury PC (SUV) & 5 & 27 & 1.34 & 29.5 & 22.0 & 13.4 & 10.0 \\
\hline Luxury PHEV (SUV) & 5 & 27 & 1.34 & 29.5 & 22.0 & 13.4 & 10.0 \\
\hline City bus & 103 & 21 & 21.54 & 72.8 & 3.4 & 44.5 & 2.1 \\
\hline Articul. bus & 155 & 21 & 32.41 & 108.8 & 3.4 & 63.4 & 2.0 \\
\hline \multirow[t]{2}{*}{ Tram } & 145 & 25 & 36.25 & 243.0 & 6.7 & 91.4 & 2.5 \\
\hline & $\begin{array}{l}\text { Vehicle gross } \\
\text { weight }[\mathrm{kg}]\end{array}$ & $\begin{array}{l}\text { Averg. } \\
\text { speed }[\mathrm{km} / \mathrm{h}]\end{array}$ & $\begin{array}{l}\text { Energy demand in } \\
\text { use }[\mathrm{kWh} / \mathrm{km}]\end{array}$ & $\begin{array}{l}\text { Equiv. fuel consumpt. } \\
\text { in use }[1 / 100 \mathrm{~km}]\end{array}$ & $\begin{array}{l}\text { Equiv. fuel consumpt. } \\
\text { in use }[1 / 100 \mathrm{Pkm}]\end{array}$ & $\begin{array}{l}\mathrm{CO}_{2} \text { e WTW }[\mathrm{g} / \\
\mathrm{km}]\end{array}$ & $\begin{array}{l}\mathrm{CO}_{2} \mathrm{e} \text { WTW }[\mathrm{g} / \\
\mathrm{Pkm}]\end{array}$ \\
\hline Pedestrian & 0 & 4 & 0.08 & 0.96 & 0.96 & 0.0 & 0.0 \\
\hline Bicycle & 18 & 12 & 0.03 & 0.35 & 0.35 & 0.0 & 0.0 \\
\hline E-bicycle & 24 & 13 & 0.04 & 0.41 & 0.41 & 7.4 & 7.4 \\
\hline Scooter & 130 & 17 & 0.32 & 3.75 & 3.41 & 91.5 & 45.8 \\
\hline E-scooter & 145 & 17 & 0.05 & 0.58 & 0.53 & 10.5 & 5.3 \\
\hline Light urban EV & 389 & 16 & 0.10 & 1.20 & 1.10 & 21.7 & 10.9 \\
\hline Subcompact PC & 986 & 16 & 0.55 & 6.46 & 6.03 & 157.7 & 39.4 \\
\hline Subcompact EV & 1248 & 16 & 0.18 & 2.08 & 1.94 & 37.5 & 9.4 \\
\hline Mid class PC & 1246 & 16 & 0.69 & 8.05 & 6.01 & 196.6 & 39.3 \\
\hline Mid class PHEV & 1599 & 16 & 0.25 & 2.88 & 2.15 & 51.8 & 10.4 \\
\hline Luxury PC (SUV) & 2281 & 16 & 1.14 & 13.24 & 9.88 & 323.2 & 64.6 \\
\hline Luxury PHEV (SUV) & 2462 & 16 & 0.32 & 3.72 & 2.78 & 67.1 & 13.4 \\
\hline City bus & 11,529 & 18 & 4.84 & 56.37 & 2.62 & 1371.5 & 13.3 \\
\hline Articul. bus & 17,055 & 18 & 5.81 & 67.65 & 2.09 & 1645.8 & 10.6 \\
\hline Tram & 33,500 & 16 & 4.55 & 53.01 & 1.46 & 955.5 & 6.6 \\
\hline
\end{tabular}

EV electric vehicle, $P H E V$ plug-in hybrid electric vehicle, $P C$ passenger car, SUV sports utility vehicle 


\section{Data acquisition and investigation of different means of transport}

Figure 1 illustrates an overview of the investigated means of transport. It includes three categories of mobility, which are named micro-mobility, motorised individual passenger transport (MIT) and public transport.

In this study, the transport mode category micromobility addresses individual transport over short distances with relatively low transportation demand. This category includes walking and the use of small and lightweight human-powered or electric-driven vehicles, e.g. bicycles, e-bikes, small scooters and other single-person vehicles. As mentioned in [7], bicycles are used for relatively short travel distances below $3 \mathrm{~km}$. In combination with public transport systems, vehicles of this category are able to face first mile-last mile issues. In this context, the term first mile-last mile describes the transportation of people and goods from a specific starting point to a transportation hub (e.g. with the use of a certain public transport system) and from a transportation hub to a final destination, [8]. In the present study, the category micromobility includes pedestrians, bicycles and electric bicycles. The category of MIT includes the use of powered two-wheelers, small urban cars and passenger cars of different size classes. Powered two-wheelers (PTW) are playing an increasing role in both transport and recreation around the world. PTW are commonly used for commuting and for touring. Small motor scooters in particular are capable of providing an economic alternative to conventional passenger cars. The number of PTW is still increasing in many developed and developing countries. Most of the world's 313 million PTW can be found in Asia (77\%), [9]. The term "PTW" is used for mopeds, scooters and motorcycles. In this paper, motor scooters with a limited top-speed of $45 \mathrm{~km} / \mathrm{h}$ driven either by internal combustion engine (ICE) or electric motor (EM) are considered. Defined by the same European vehicle category $\mathrm{L}$ as stated for PTW, [1], small urban cars can be defined as a niche vehicle type, which is placed between powered twowheelers and full-sized passenger cars. Vehicles of this category are designed specifically for urban boundary conditions, such as those with reduced driving distances and parking space. These vehicles are characterised by a narrow shape, small turning circle and low parking space demand. One example of this vehicle type is shown in Fig. 2.

Figure 3 provides an overview of the methodology for investigation applied in the present study. The data is collected based on literature research, computer simulation as also extensive testing and measurement of various vehicles in different urban areas.

\section{Transport capacity and occupancy rates}

Maximum numbers of persons that can be carried, vehicle dimensions and vehicle gross weights are found in technical specification publications for the representative vehicles of each size class. The occupancy rate describes the ratio of

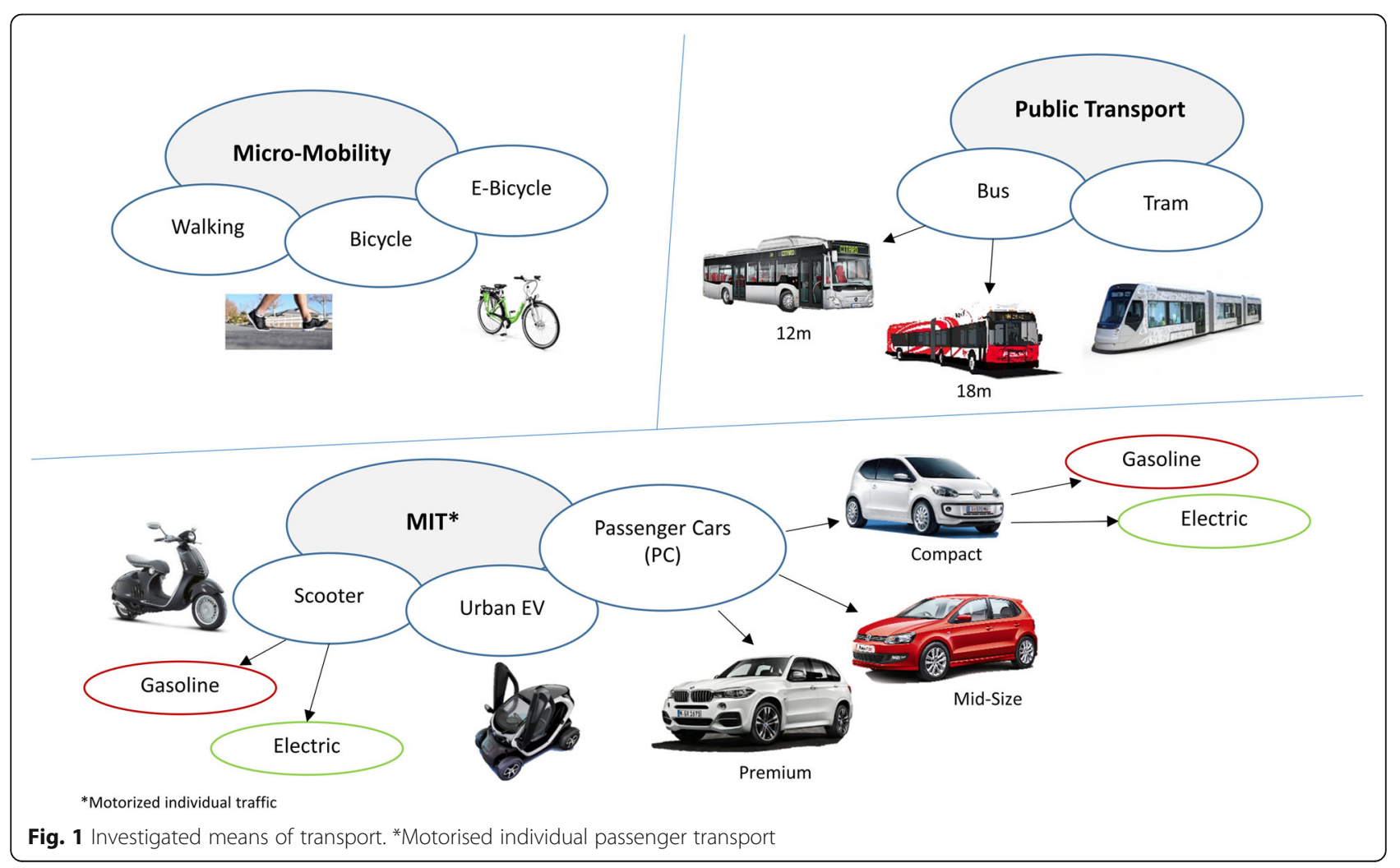




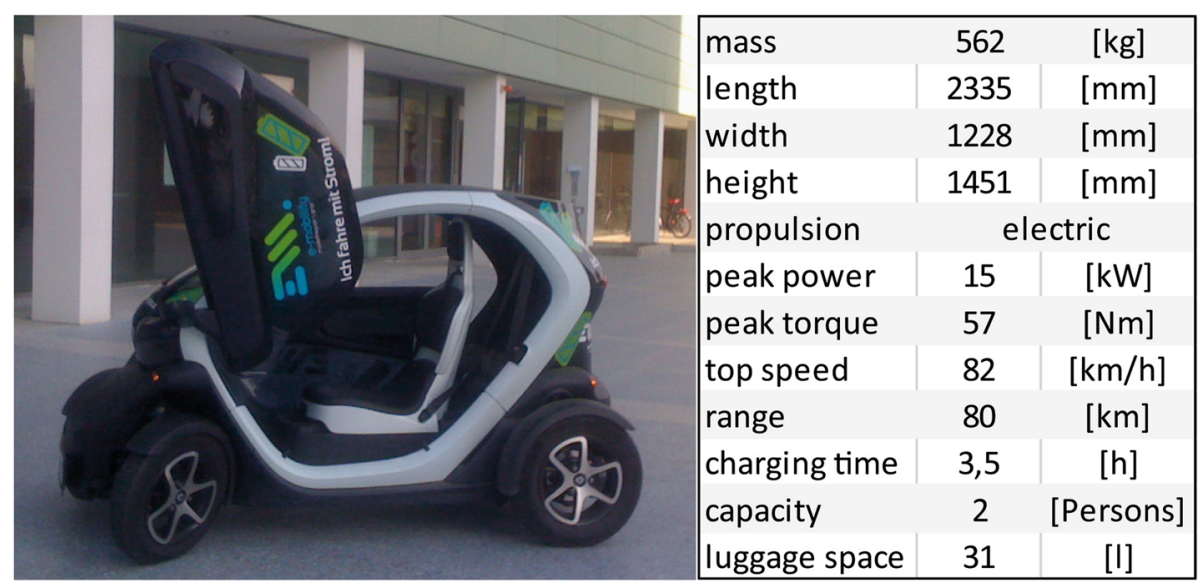

Fig. 2 Urban electric vehicle Renault Twizy [1]

the mean number of transported persons per vehicle to the maximum possible number of people that can be carried. Stated occupancy rates are mainly based on publications from mobility inquiries, e.g. $[7,10]$. The mean occupancy rates of public transport vehicles are derived from data available from a public transport service provider in Graz, Austria, [11]. Stated occupancy rates represent a mean value over an entire typical working day in the city of Graz. Figure 4 illustrates this time-dependent occupation of public transportation in detail, where peaks can be detected between seven and eight o'clock in the morning.

\section{Speed-dependent traffic space demand and parking space demand}

Data mining and investigation of the space demand of different modes of transport in traffic and for parking were based on several technical data sources and approaches, which are described as follows.

Equation 1 describes the related traffic space demand $A_{t \_i}$ in fluent traffic:

$$
A_{t \_i}=\frac{\left(l 1_{i}+s_{f \_i}\right) \frac{w}{n_{\mathrm{p} \_i}}}{n_{\mathrm{eff} \_i}}, i=1,2 \ldots n_{\mathrm{MT}}
$$

$A_{t \_i}\left(\mathrm{~m}^{2}\right)$ Related traffic space demand of vehicle $i$ in fluent traffic

$l 1_{i}(\mathrm{~m})$ Length of vehicle $i$

$s_{f_{-} i}(\mathrm{~m})$ Distance to front vehicle, based on a speeddependent approach for MIT

$w(\mathrm{~m})$ Lane width, assumed to $3 \mathrm{~m}$

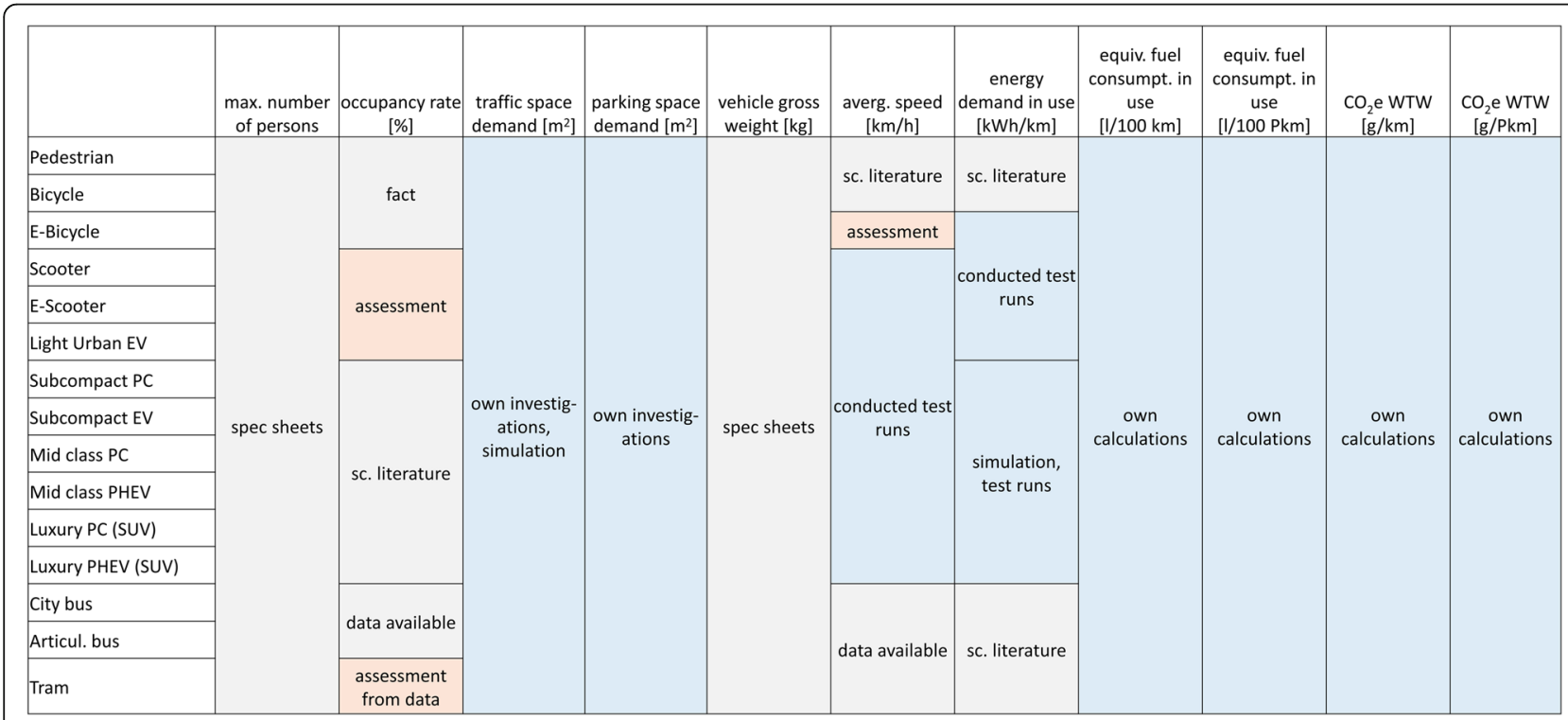

Fig. 3 The investigation methodology. EV electric vehicle, PHEV plug-in hybrid electric vehicle, PC passenger car, SUV sports utility vehicle 


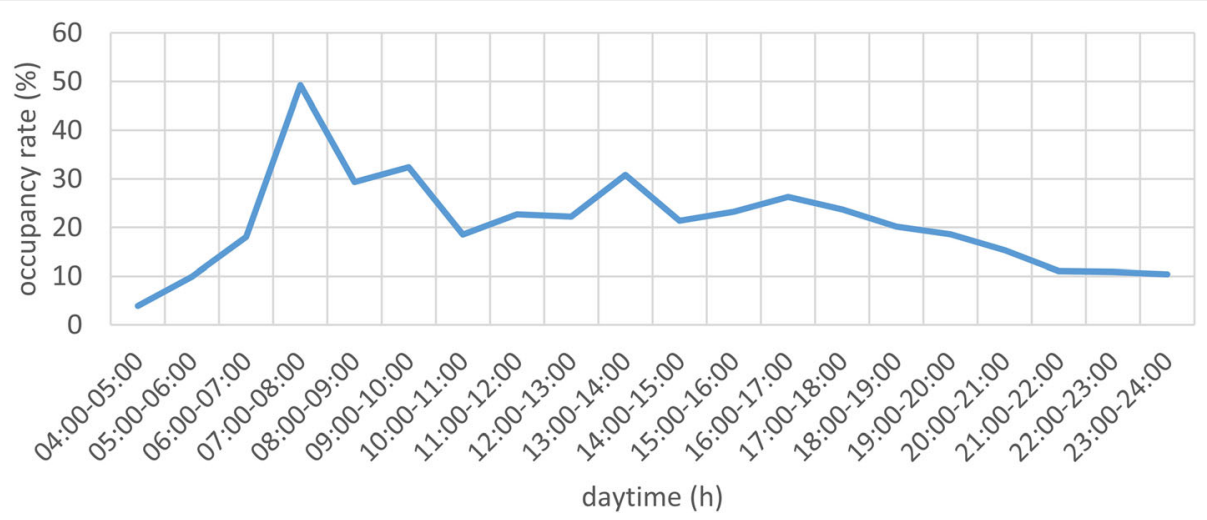

Fig. 4 Time variation curve of an occupancy rate (\%). Mean value from various bus-lines during one typical workday in Graz, Austria [12]

$n_{\mathrm{p} \_i}$ (\#) Possible number of parallel driving vehicles in one lane

$n_{\text {eff } i}$ (\#) Effective number of persons in vehicle $i$, based on the space offer and occupancy rate

$n_{\mathrm{MT}}(\#)$ Number of compared means of transport

The distance to the preceding vehicle for all vehicles is influenced by a speed-dependent approach. After observation of fluent traffic at different spots with different mean velocities in the urban area of Graz, a minimum time period of $2 \mathrm{~s}$ is defined between each pair of vehicles. According to this defined time period, a time-dependent distance between the front of vehicle $i$ and the rear section of the preceding vehicle can be calculated according to Fig. 5 .

At low speed (below $10 \mathrm{~km} / \mathrm{h}$ ), the minimum distance is set to $1 \mathrm{~m}$, according to results from the conducted observation. The maximum speed limit of the observation was $30 \mathrm{~km} / \mathrm{h}$. The possible number of parallel driving vehicles in one lane, $n_{\mathrm{p} \_}$, is set at 1 for public transport and cars, at 2 for powered two-wheelers, and at 3 for micro-mobility and walking. For investigated public transport modes (buses and tram), the minimum distance to the front vehicle was determined as one vehicle length (shown in Table 1).

Equation 2 describes the calculation of the related parking space demand $A_{\mathrm{p}_{-} i}$ for each vehicle $i$.

$$
\begin{aligned}
A_{\mathrm{p} \_i} & =\frac{\left(l 1_{i}+l_{\mathrm{p} \_i}\right)+\left(w 1_{i}+2 w_{\mathrm{p} \_i}\right)}{n_{\mathrm{eff} \_i}}, i \\
& =1,2 \ldots n_{\mathrm{MT}}
\end{aligned}
$$

$A_{\mathrm{p} \_i}\left(\mathrm{~m}^{2}\right)$ Related space demand of vehicle $i$ while parking

$l 1_{i}(\mathrm{~m})$ Length of vehicle $i$

$l_{\mathrm{p}_{-} i}(\mathrm{~m})$ Longitudinal distance to front vehicle, according to measurements

$w_{1 \_i}(\mathrm{~m})$ Width of vehicle, including exterior parts (e.g. mirrors)

$w_{\mathrm{p} \_i}(\mathrm{~m})$ Required additional lateral parking space

$n_{\text {eff }_{i} i}(\#)$ Effective number of persons in vehicle $i$, based on the space offer, designated occupancy rate

$n_{\mathrm{MT}}(\#)$ Number of compared means of transport

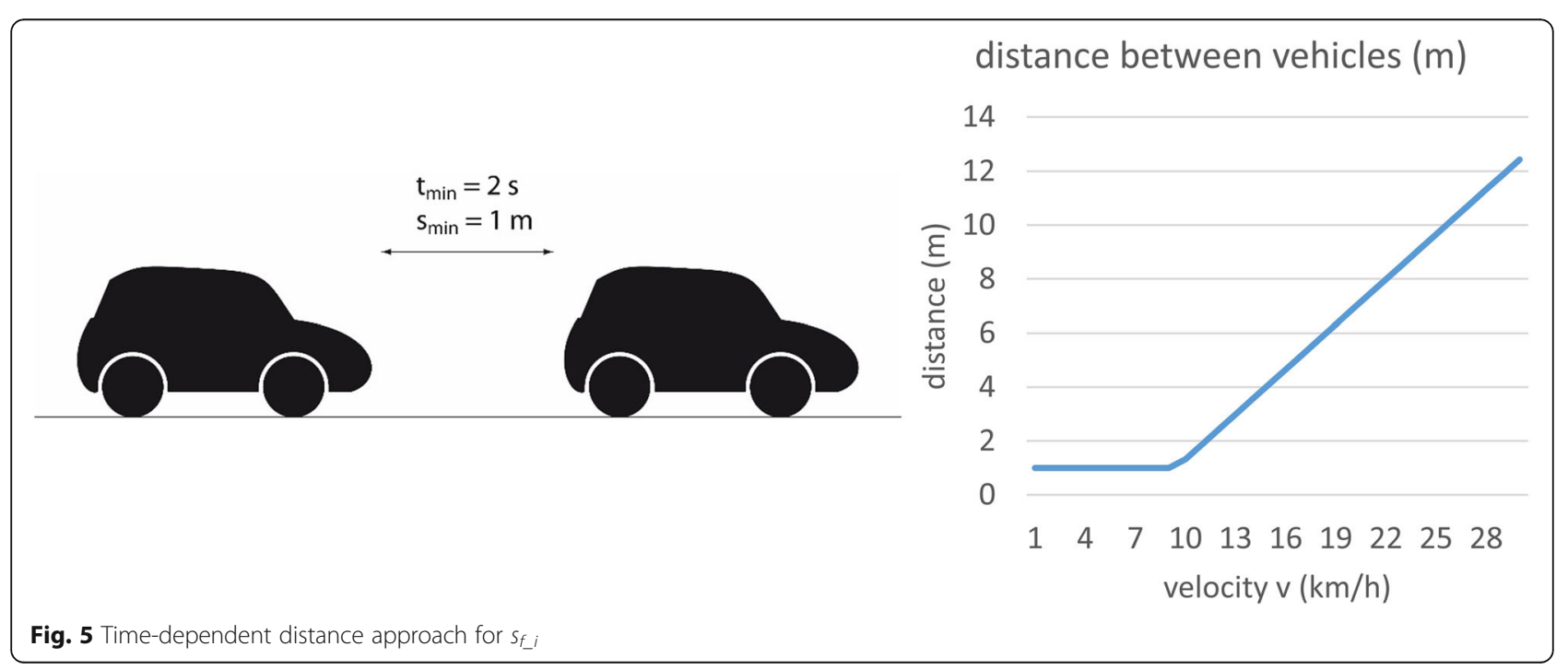


According to the measurements conducted and the defined mean values, $l_{\mathrm{p} i}$ is $0.9 \mathrm{~m}$ for passenger cars and $0.2 \mathrm{~m}$ for PTW. Length $w_{\mathrm{p} i}$ is $0.15 \mathrm{~m}$ for passenger cars and $0.25 \mathrm{~m}$ for PTW. Additional parking space for public transport vehicles is set to $2 \mathrm{~m}$ for $l_{\mathrm{p}_{-} i}$ and $0.2 \mathrm{~m}$ for $w_{\mathrm{p}_{-} i}$.

\section{Average journey speed}

The average journey speed describes the distance travelled divided by travel time. In contrast to the average speed, the average journey speed also considers delay in congestion and at traffic lights. Average journey speed values for walking and bicycling is derived from measurements. Since there is no separate data available for electric bikes, the defined values are based on measurements and assumptions of the share of human power and electric power usage. The MIT data is derived from test runs conducted in the urban area of Graz, Austria. A mean value of 16 to $17 \mathrm{~km} / \mathrm{h}$ is determined for every type of vehicle for MIT in the innerurban area, $[1,12]$. The public transport vehicle data is from analysis of the information provided on the websites of transport service providers, e.g. [11], and measurement drives that were performed.

\section{Energy consumption and $\mathrm{CO}_{2}$ equivalent emissions}

Energy consumption for walking and bicycling is derived from [13], based on the nutritional requirement of a human being. Therefrom, specified values in kilojoule per minute have been converted in relation to the particular average journey speed $(4 \mathrm{~km} / \mathrm{h}$ for walking and $12 \mathrm{~km} / \mathrm{h}$ for bicycling). Additionally, the metabolic rate at rest has been subtracted. The metabolic rate at rest defines the basic energy demand of a living being at no physical activity. This share of energy consumption is also present during, e.g., driving a car or using public transport. Energy consumption of MIT is derived from [1, 3, 14, 15]. The public transport data is derived from $[16,17]$. The determination of the equivalent gasoline fuel consumption for electric-driven vehicles follows Eq. 3.

$$
b_{\mathrm{f}_{-} i}=\frac{b_{\mathrm{e} \_i}}{H_{u} \rho_{f}}, \quad i=1,2 \ldots n_{\mathrm{MT}}
$$

$b_{\mathrm{f}_{-} i}(\mathrm{l} / \mathrm{km})$ Equivalent gasoline fuel consumption of vehicle $i$

$b_{\mathrm{e}_{-} i}(\mathrm{kWh} / \mathrm{km})$ Electric energy consumption of vehicle $i$ $H_{u}(\mathrm{kWh} / \mathrm{kg})$ Heat value of gasoline, $H_{u}=11.6 \mathrm{kWh} / \mathrm{kg}$ $\rho_{\mathrm{f}}(\mathrm{m})$ Fuel density, $0.74 \mathrm{~kg} / \mathrm{l}$

$n_{\mathrm{MT}}(\#)$ Number of compared means of transport

$\mathrm{CO}_{2}$ equivalent $\left(\mathrm{CO}_{2} \mathrm{e}\right)$ emissions for the in-use phase are based on calculations of the energy consumption in operation and include the resulting $\mathrm{CO}_{2} \mathrm{e}$ emissions for the energy supply of both electric energy and fuel production (gasoline and diesel). The energy supply sector data stem from life cycle inventory models, [18]. $\mathrm{CO}_{2} \mathrm{e}$ emissions of electric energy production base on the average Austrian electric energy mix $(210 \mathrm{~g} / \mathrm{kWh})$, [18], which is valid for the use of every electric-powered vehicle in the present study, including electric bicycle, electric scooter, passenger cars and tram. The reason for the choice of this relatively low emission value for electric energy production is to discuss its influence in relation to the use of fossil energy sources on the final result.

The collected data are summarised and illustrated in Table 1.

\section{Evaluation method: weighted traffic performance index (WTPI)}

In order to compare $n_{\mathrm{MT}}$ different means of transport (e.g. a mid-size class passenger car and a city bus) in reference to one specific performance criterion (e.g. the averaged fuel consumption per passenger), a developed traffic performance index $T P I_{i}$ is introduced, see Eq. 4:

$$
T P I_{i}=10 \min \left(\frac{V_{t}}{V_{M_{-}}}, 1\right), \quad i=1,2 \ldots n_{\mathrm{MT}}
$$

$T P I_{i}$ Traffic performance index in a certain category

$V_{t}$ A specific target value for this criterion

$V_{M \_i}$ Actual value for the considered case

$n_{\mathrm{MT}}$ Number of compared means of transport

A specific target value $V_{t}$ of a particular criterion is set, such that the related index $T P I_{i}$ will reach the top grade 10 if the $i$ th means of transport can fulfil or even exceed this target. This value is related to the actual value for this case, $V_{M_{-}}$, such that $0<T P I_{i} \leq 10$.

The comparison of $n_{\mathrm{MT}}$ means of transport in the context of $n_{\mathrm{PC}}$ different performance criteria is then extended to the weighted traffic performance index $W T P I_{i}$, which is defined as

$$
\begin{aligned}
W T P I_{i} & =\sum_{j}^{n_{\mathrm{PC}}} f_{W j} \operatorname{TPI}_{i}, \quad i=1,2 \ldots n_{\mathrm{MT}}, \quad j \\
& =1,2, \ldots n_{\mathrm{PC}}
\end{aligned}
$$

$W T P I_{i}$ weighted traffic performance index $f_{\mathrm{Wj}}$ Weighting factors

$n_{\mathrm{PC}}$ Number of different performance criteria

The weighting factors of the $n_{\mathrm{PC}}$ performance criteria sum up to 1 , corresponding to $100 \%$. Again, it holds 0 (lowest grade) $<W T P I_{i} \leq 10$ (best grade) . 


\section{Results and discussion Data collection}

Table 1 presents a comparison of the technical characteristics for the means of transport that are considered.

As an illustrated example of the collected data, Fig. 6 shows the absolute equivalent fuel consumption for the use of different modes of transport (left) in comparison with the relative equivalent fuel consumption per person (right). Hence, it points out the influence of the occupancy rate on the relative energy demand. The highest values can be detected for the use of passenger cars with internal combustion engines. The reason for this can be found in a relatively low driveline efficiency in comparison with a relatively low occupancy rate. The absolute energy consumption for public transport vehicles is high, however, due to the relatively high occupancy rates and the personrelated energy consumption is relatively low. The lowest energy consumption values can be determined for the use of bicycles and small electric-driven vehicles, as the results show.

As another example, Fig. 7 illustrates the defined traffic (left) and parking (right) space demands, based on the developed approaches at a mean vehicle speed of $17 \mathrm{~km} / \mathrm{h}$. Based on the theoretical approach of two vehicles driving parallel in one lane, powered two-wheelers require half the space of a passenger car in fluent traffic. Aside from walking, public transport is singled out for its relatively low results in traffic space demand due to high occupation levels. Similar relations are obtained for results of parking space demands.

\section{Evaluation}

The developed methodology of evaluation is based on a broad range of different criteria, describing technical, ecological and economic characteristics and effects of the use of different modes of transport. In the present study, four criteria are considered for the comparison. In urban, areas especially space requirements are important. Focusing on resource demands in use and climate change, the equivalent fuel consumption is also taken into consideration. Furthermore, the vehicle mass is defined as a representative for resource demands for vehicle production in this first step of evaluation. The possible average journey speed is considered in order to focus on user demands. The four criteria considered can be seen in Table 2, including the defined target values and the applied weighting factors for each criterion.

As a result of the study, Figs. 8, 9 and 10 show the calculated weighted traffic performance indices WTPI for the use of different modes of transport in urban areas, based on the collected data, calculated specifications and defined categories, as also the pre-defined weighting factors into consideration. A high index is a reference for a high suitability of a certain mode of transport.

Taking the collected data and pre-defined criteria into consideration, the highest indices in scenario balanced are achieved by human-powered modes of transport (walking and bicycle). Due to a relatively low resource demand, small electric-driven vehicles achieve a similar level to that of public transport vehicles. An interesting

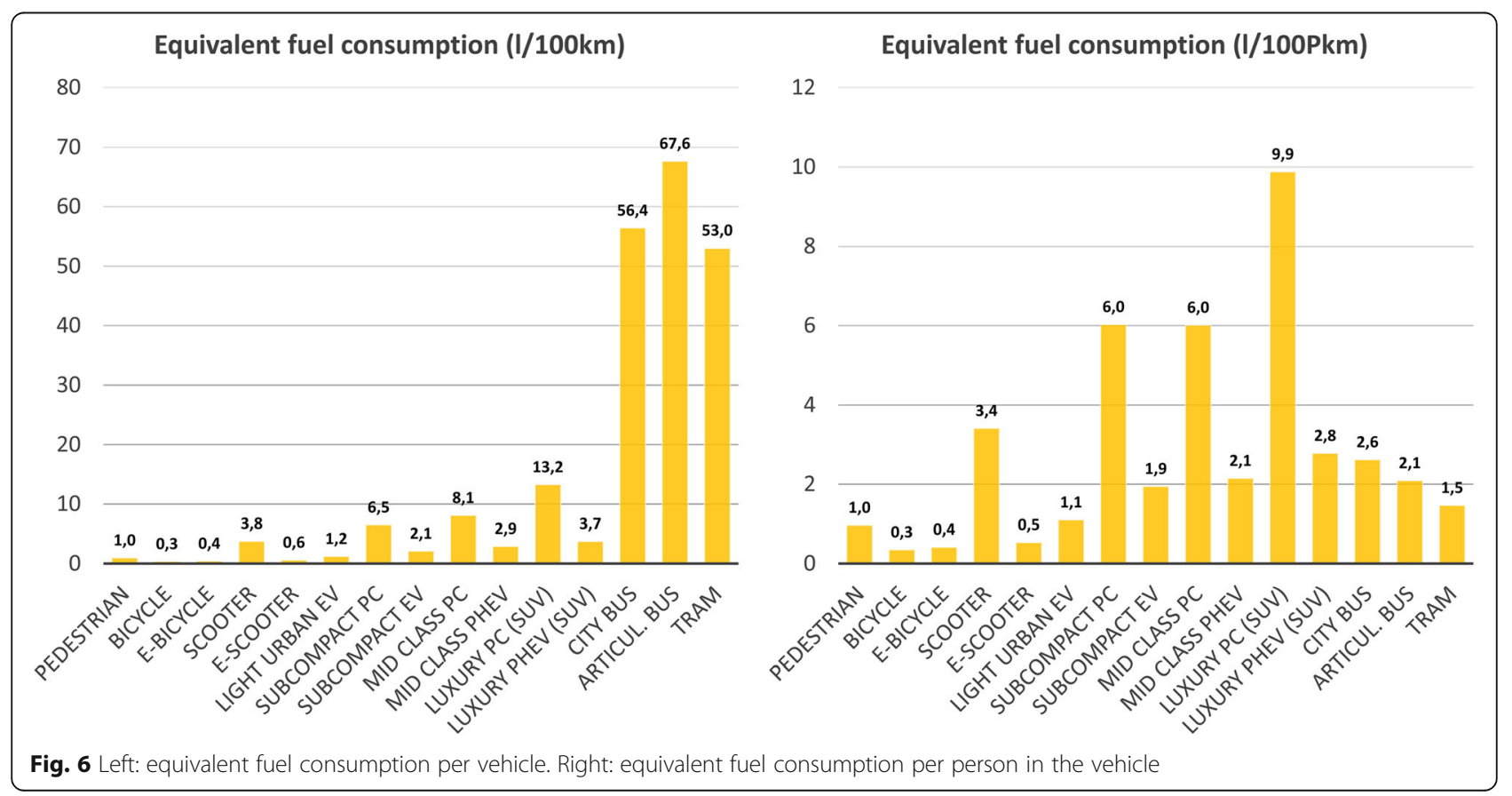




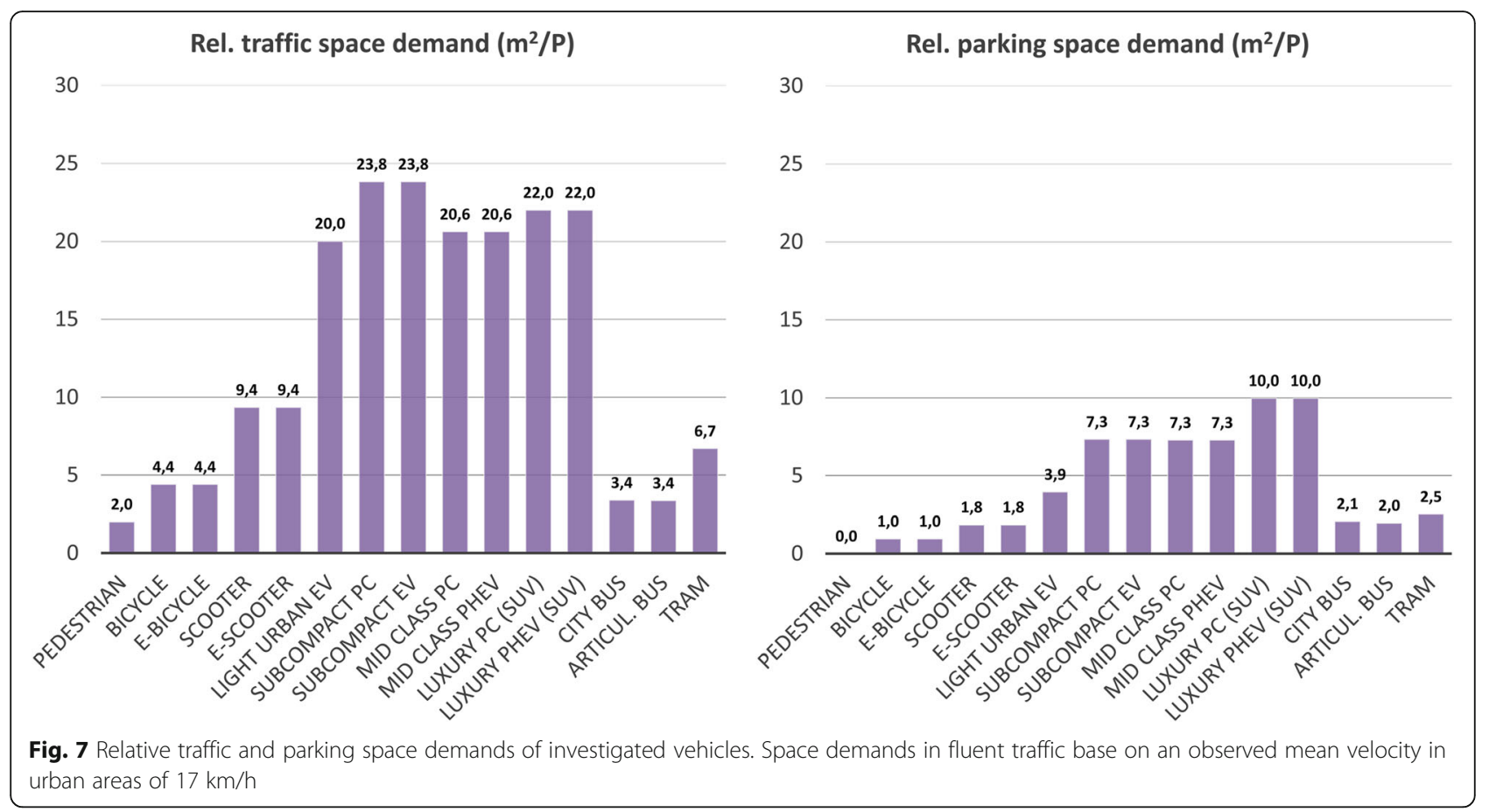

point is the relatively high suitability of the electric scooter. The use of passenger cars, either fuel or electric driven, results in the lowest values. In the user optimum scenario, the most important criterion is the average journey speed. A broad range of the generated results thus achieve relatively similar levels. In combination with the second important criterion-the fuel consumption, addressing the direct costs of mobility-electric scooters and bicycles achieve the highest level in this scenario. At resource optimum, mainly influenced by relative mass and equivalent fuel consumption, again walking, the use of bicycles and electric scooters achieve relatively high indices. Taking the three illustrated scenarios into consideration, small vehicles from the category micro-mobility can be seen as the most efficient modes of transport in urban areas after public transport systems.

\section{Conclusions}

The study provides a database with specific mobilityrelated criteria and parameters, which include technical characteristics and the effects of the use of different vehicles and means of transportation in urban areas. A newly introduced methodology enables an objective evaluation of various means of transport for urban areas, whereby different weighting factors are considered for addressing the specific demands of various stakeholders. A subsequently performed evaluation points to the potential of different means of transport taking specifically defined priority-scenarios into consideration. Considering the varying demands of different stakeholders, the weighting factors are exemplary set to show their influence on the calculated evaluation results. As one important cognition, it is clearly shown that individual-motorised traffic, dominated by the use of private passenger cars, represents the most inefficient form of inner-urban mobility. On the other hand, small vehicles from the category micromobility can be seen as efficient modes of transport in urban areas, revealing their great potential for contributing to sustainable urban mobility. One disadvantage is the limited action radius, as can exemplary be found in [1]. This issue could be addressed, however, by the combination with public transportation in first-mile/last-mile concepts. By application of selected scenarios, it is shown that the generated database and calculation method

Table 2 Defined performance criteria, target values and applied weighting factors

\begin{tabular}{llllll}
\hline TPI categories & \multicolumn{2}{l}{ Target values $V_{t}$} & \multicolumn{2}{l}{ Weighting factor $f_{\text {wi }}$} \\
\cline { 5 - 6 } & & & Balanced (\%) & User optimum (\%) & Resource optimum (\%) \\
\hline Related mass per person & 75 & $\mathrm{~kg}$ & 25 & 5 & 20 \\
Rel. traffic space demand & 2 & $\mathrm{~m}^{2}$ & 25 & 5 & 20 \\
Average speed & 32 & $\mathrm{~km} / \mathrm{h}$ & 25 & 70 & 5 \\
Equivalent fuel consumption & 0.3 & $1 / 100 \mathrm{Pkm}$ & 25 & 20 & 55 \\
\hline
\end{tabular}




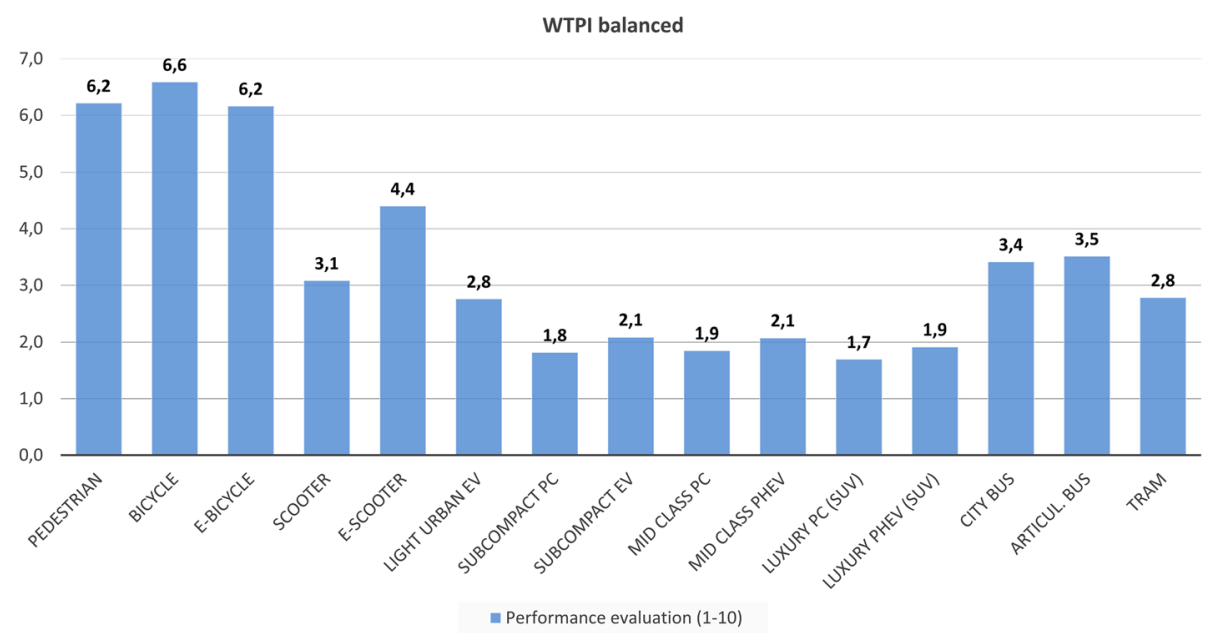

Fig. 8 WTPI values, scenario balanced (25\% related mass, 25\% related traffic space demand, 25\% average journey speed, 25\% equiv. fuel consumption)

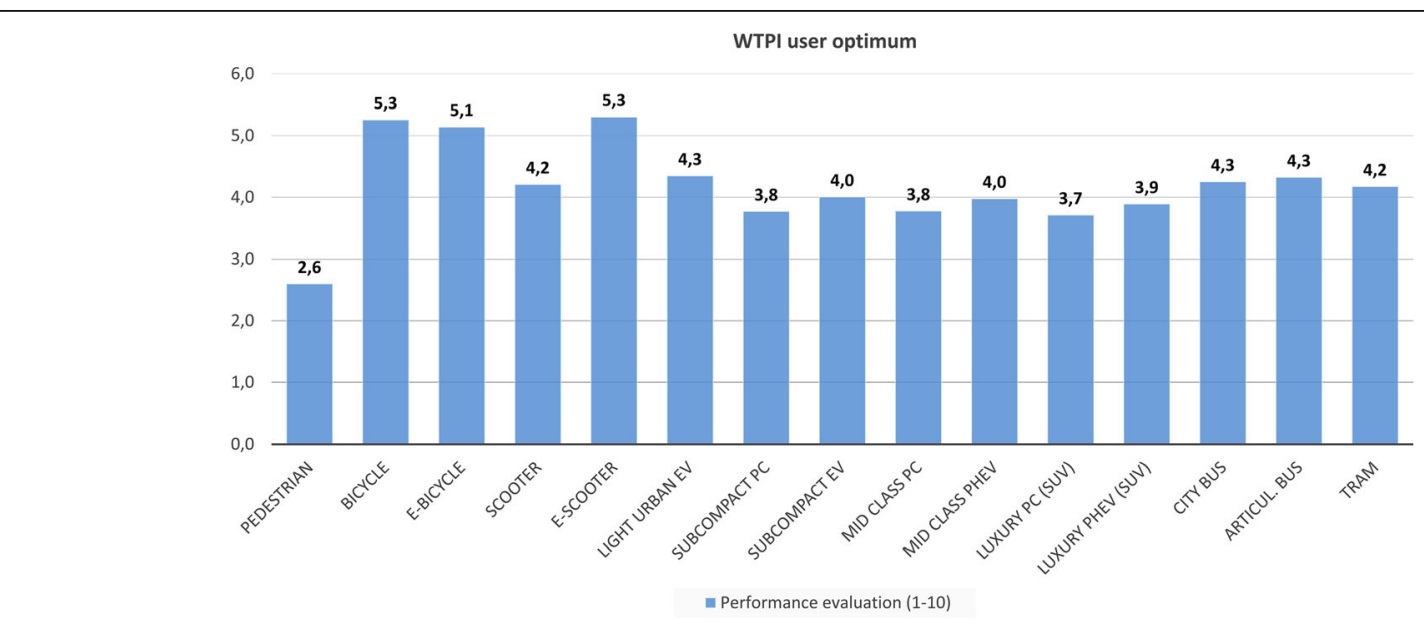

Fig. 9 WTPI values, scenario user optimum (5\% related mass, 5\% related traffic space demand, 70\% average journey speed, 20\% equiv. fuel consumption)

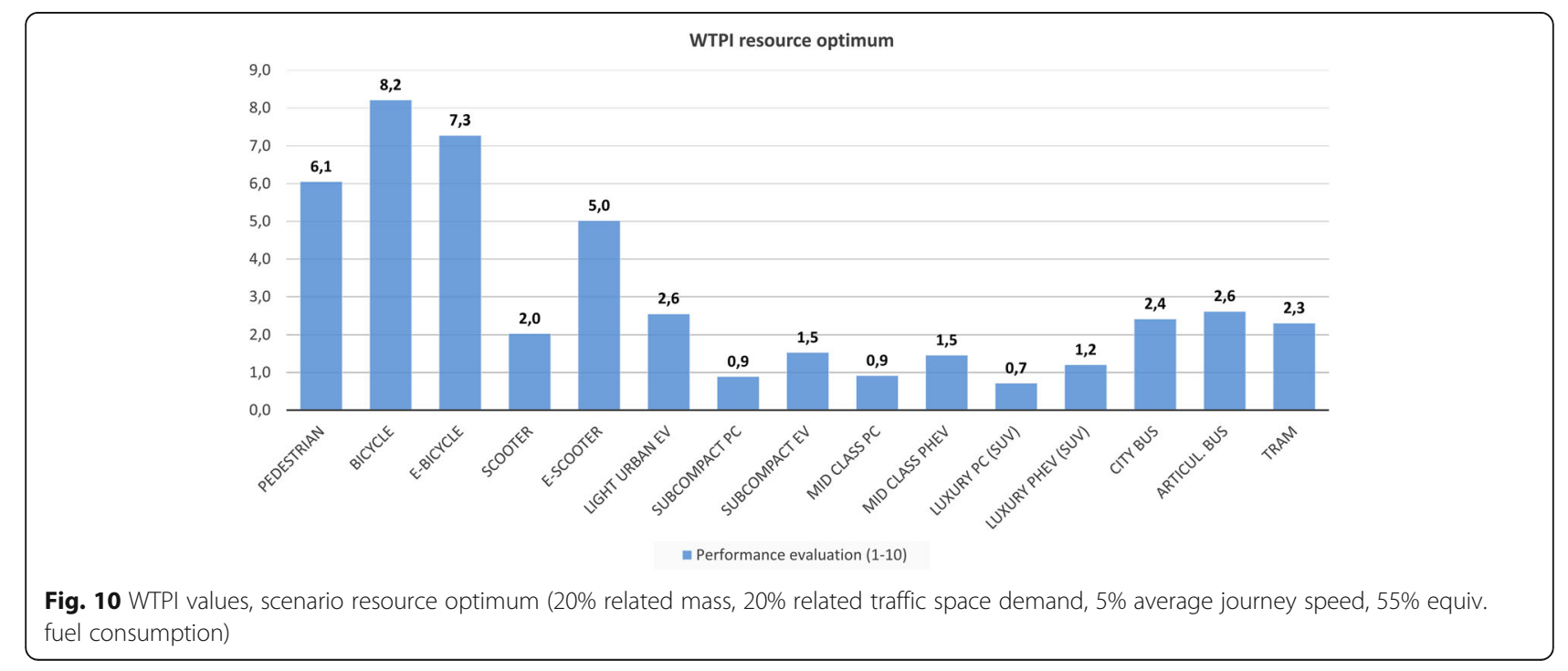


enable an objective evaluation of different modes of transport in urban areas. This can contribute to the development and implementation of new mobility solutions for successful sustainable urban development and energy supply strategies.

The approach introduced here is by no means limited to the exemplary transportation technologies and traffic scenarios that are included in this work. The database can be extended by additional vehicles and a much broader range of user-related, economic and ecologic criteria (e.g. total costs of ownership and usage, efforts for infrastructure construction and maintenance, vehicle combinations, vehicle production and lifetimerelated aspects, as well as health-related criteria). Extensions also can consider the objective development of additional weighting factors according to specific stakeholder demands.

\section{Acknowledgements}

The authors extend their grateful thanks for the data contributions and support received from the various sources as given in the references.

\section{Authors' contributions}

$\mathrm{HB}$ and $\mathrm{WH}$ conceptualised and structured the paper. HB was responsible for the data collection and analysis, supported by advice from other authors. The paper was jointly drafted and developed in its entirety by all authors with the intention of providing a current status report. All authors read and approved the final manuscript.

\section{Competing interests}

The authors declare that they have no competing interests.

\section{Publisher's Note}

Springer Nature remains neutral with regard to jurisdictional claims in published maps and institutional affiliations.

\section{Author details}

'Institute of Automotive Engineering, Graz University of Technology, Inffeldgasse 11/2, 8010 Graz, Austria. ${ }^{2}$ IBV Fallast—Ingenieurbüro für Verkehrsplanung und Umweltplanung, Wastiangasse 14, 8010 Graz, Austria.

Received: 6 March 2017 Accepted: 24 January 2018

Published online: 07 March 2018

\section{References}

1. Brunner H, Hirz M (2012) Urbaner Personenverkehr-Rahmenbedingungen für neue Fahrzeugkonzepte, report, Institute of Automotive Engineering. Graz University of Technology, Austria

2. Follmer, R.; Gruschitz, D.; Lenz, B.; Nobis, C. et al.: Mobilität in Deutschland, report, 2008

3. Haas R et al (2009) Entwicklung von Szenarien der Verbreitung von PKW mit teil-und vollelektrifiziertem Antriebsstrang unter verschiedenen politischen Rahmenbedingungen. Report, TU Wien. Institut für elektrische Anlagen und Energiewirtschaft, Vienna

4. Verkehrsclub Österreich (VCÖ) (2014) Mobilität mit Zukunft 2/2014. Lebensraum Stadt und Mobilität, Vienna ISBN 3-901204-81-4

5. Weidmann $U$ et al (2011) Application areas of various means of transportation in agglomerations. Report, ETH Zürich. Institut für Verkehrsplanung und Transportsysteme (IVT), Switzerland

6. Marique A-F, Reiter S (2011) A method for evaluating transport energy consumption in suburban areas. Environ Impact Assess Rev 33(1). https:// doi.org/10.1016/j.eiar.2011.09.001.

7. Sammer, G.; et al.: Mobilitätsverhalten der Grazer Wohnbevölkerung. Report, Graz, 2008
8. Brunner H, Hirz M, Walzel B (2016) Integration of new urban vehicles in transport systems and mobility concepts. FISITA World Automotive Congress, South Korea

9. Harworth N (2012) Powered two wheelers in a changing world_challenges and opportunities. In: Accident analysis and prevention 44. https://doi.org/ 10.1016/j.aap.2010.10.031.

10. Fallast, K.; Klockler, T:: Kordonerhebung Graz-motorisierter Individualverkehr. Report, Ingenieurbüro für Verkehrswesen, Graz, 2003

11. Holding Graz. URL http://www.holding-graz.at/. 11/9/2016

12. Skalka M, Brunner H (2013) Erhebung von Mobilitätsdaten im Großraum Graz. Bachelor-thesis, TU Graz, Institute of Automotive Engineering, Graz

13. Kraut $\mathrm{H}$ et al (1981) Der Nahrungsbedarf des Menschen. Springer. https:// doi.org/10.1007/978-3-642-72338-4. isbn:9783642723384

14. Brunner $\mathrm{H}$, Hirz M (2013) Verschiedene Antriebe im Fokus differenzierter Nutzungsmuster. Report, Institute of Automotive Engineering, Graz University of Technology, Austria

15. Gehringer B, Tober W (2012) Batterieelektrische Fahrzeuge in der Praxis. Austrian Society of Automotive Engineers, Vienna

16. Kies, A. et al.: EHEV — eco drive for hybrid electric vehicles. Report, TU Graz, Institute of Internal Combustion Engines and Thermodynamics, 2013

17. Gradwohl, R; Ensbacher, R.: Energiesparende Maßnahmen bei der Wiener Niederflurstraßenbahn ULF. $41^{\text {st }}$ Conference Modern Rail Vehicles, 2012

18. GEMIS: Global emissions modell for integrated systems, URL http://www. iinas.org/gemis.html. 11/9/2016

\section{Submit your manuscript to a SpringerOpen ${ }^{\mathcal{O}}$ journal and benefit from:}

- Convenient online submission

- Rigorous peer review

- Open access: articles freely available online

- High visibility within the field

- Retaining the copyright to your article

Submit your next manuscript at $\boldsymbol{\nabla}$ springeropen.com 